\title{
Impact of body mass index on perioperative outcomes during the learning curve for robot-assisted radical prostatectomy
}

\author{
Venu Chalasani, MB BS, FRACS; Carlos H. Martinez, MD; Darwin Lim, MD; Reem Al Bareeq, MD; \\ Geoffrey R. Wignall, MD; Larry Stitt, MSC; Stephen E. Pautler, MD, FRCSC
}

See related article on page 255 .

\section{Abstract}

Introduction: Previous studies of robotic-assisted radical prostatectomy (RARP) have suggested that obesity is a risk factor for worse perioperative outcomes. We evaluated whether body mass index (BMI) adversely affected perioperative outcomes.

Methods: A prospective database of 153 RARP (single surgeon) was analyzed. Obesity was defined as $B M I \geq 30 \mathrm{~kg} / \mathrm{m}^{2}$; normal $\mathrm{BMI}<25 \mathrm{~kg} / \mathrm{m}^{2}$; and overweight as 25 to $30 \mathrm{~kg} / \mathrm{m}^{2}$. Two separate analyses were performed: the first 50 cases (the initial learning curve) and the entire cohort of 153 RARP.

Results: In the initial cohort of 50 cases ( 14 obese patients), there was no statistically significant difference with regards to operative times, port-placement times and estimated blood loss (EBL). Length of stay (LOS) was longer in the obese group (4.3 vs. 2.9 days); BMI remained an independent predictor of increased LOS on multivariate linear regression analysis $(p=0.002)$. There was no statistically significant difference in the postoperative outcomes of leak rates, margin rates and incisional herniae. In the entire cohort, when comparing obese patients to those with a normal BMI, there was no statistically significant difference in operative times, EBL, LOS, or immediate postoperative outcomes. However, on multivariate linear regression analysis, BMI was an independent predictor of increased operative time $(p=0.007)$.

Conclusion: Obese patients do not have an increased risk of blood loss, positive margins or the postoperative complications of incisional hernia and leak during the learning curve. They do, however, have slightly longer operative times; we also noted an increased LOS in our first 50 cases.

\section{Résumé}

Introduction : Des études antérieures sur la prostatectomie radicale assistée par robot (PRAR) ont laissé entendre que l'obésité était un facteur de risque de complications périopératoires. Nous avons évalué si I'indice de masse corporelle (IMC) affectait de façon négative les résultats de l'opération.

Méthodologie : Une base de données prospective comptant 153 PRAR (effectuées par un seul chirurgien) a été analysée. On a défini l'obésité comme un IMC $\geq 30 \mathrm{~kg} / \mathrm{m}^{2}$, un IMC normal étant $<25 \mathrm{~kg} / \mathrm{m}^{2}$, et un IMC entre 25 et $30 \mathrm{~kg} / \mathrm{m}^{2}$ représentant un surplus de poids. Deux analyses distinctes ont été réalisées : les 50 premiers cas (courbe d'apprentissage initiale) et la cohorte entière des 153 patients ayant subi une PRAR.
Résultats : Dans la cohorte initiale de 50 cas (dont 14 patients obèses), on n'a noté aucune différence significative sur le plan statistique en ce qui concerne la durée de l'opération, le temps requis pour installer l'accès vasculaire et la perte de sang approximative. La durée du séjour était plus longue dans le groupe des patients obèses (4,3 contre 2,9 jours), et I'IMC est demeuré un facteur indépendant de prédiction d'une durée prolongée du séjour lors de l'analyse de régression linéaire multivariée $(p=0,002)$. Aucune différence significative sur le plan statistique n'a été notée dans les résultats postopératoires quant aux taux de fuite, aux taux de marges positives et aux hernies incisionnelles. Dans toute la cohorte, on n'a noté aucune différence significative sur le plan statistique entre les patients obèses et les patients dont l'IMC était normal en ce qui a trait à la durée de l'opération, la perte de sang, la durée du séjour et les résultats postopératoires immédiats. Néanmoins, I'IMC s'est révélé un facteur de prédiction indépendant d'une durée prolongée de l'opération lors de l'analyse de régression linéaire multivariée $(p=0,007)$.

Conclusion : Les patients obèses ne courent pas un risque plus élevé de perte de sang, de marges positives ou de complications postopératoires comme une hernie incisionnelle ou une fuite pendant la période de la courbe d'apprentissage du chirurgien. Ils nécessitent toutefois une opération légèrement plus longue; une durée plus longue du séjour a aussi été notée chez les 50 premiers cas.

Can Urol Assoc J 2010;4(4):250-4

\section{Introduction}

Obesity, defined as a body mass index (BMI) greater than $30 \mathrm{~kg} / \mathrm{m}^{2}$, is continuing to be a public health problem in the United States; the latest results from the Centers for Disease Control and Prevention (CDC) analysis of the 2007 Behavioral Risk Factor Surveillance System survey indicate that $26.4 \%$ of all male respondents were obese. Amongst those males most likely to undergo a radical prostatectomy (i.e., ages 50-70), the prevalence of obesity was about $30 \%{ }^{1}$ This problem is not limited to the United States; similar trends are emerging from Europe, ${ }^{2}$ China $^{3}$ and India. ${ }^{4}$ In England, it is estimated that the prevalence of obesity will be a staggering $32.1 \%$ by 2012 if current trends continue. ${ }^{5}$

It is well-established that obese patients have higher rates of chronic diseases and higher rates of mortality. ${ }^{6}$ Previous 
studies of robotic-assisted radical prostatectomy (RARP) have found obesity to be a risk factor for increased operative time,, 78 anastomosis time, ${ }^{9}$ port closure time, ${ }^{9}$ blood loss ${ }^{10}$ and positive surgical margins. ${ }^{11}$ Given these findings, surgeons starting a robotic program are often advised to start with patients with a normal BMI. We evaluated whether BMI adversely affected perioperative outcomes, within the learning curve (defined as the first 50 cases) and within the overall cohort of 153 cases.

\section{Methods}

A prospective collected database of 153 RARPs performed by a single surgeon between April 2005 and April 2008 was analyzed (36 months). The first 50 cases were performed over a 19-month period. This study has received institutional ethics approval from the University of Western Ontario, London, Ontario, Canada, and is registered with the National Institute of Health (ClinicalTrials.gov Identifier NCT00292019). All patients provided informed consent. Information was collected prospectively on standardized patient case report forms, starting with the first preoperative visit.

All patients with localized low- or intermediate-risk biopsy proven prostate cancer were considered potential candidates for RARP. Patients were not excluded based on BMI. Obesity was defined as BMI $\geq 30 \mathrm{~kg} / \mathrm{m}^{2}$, normal BMI $<25 \mathrm{~kg} / \mathrm{m}^{2}$, and overweight as $25-30 \mathrm{~kg} / \mathrm{m}^{2}$. Two separate analyses were performed: the first 50 cases (i.e., the initial learning curve) and, subsequently, the entire cohort of 153 RARPs, as the exact cutoff point defining the end of the learning curve remains controversial.

Within the initial learning curve (i.e., the first 50 cases), the analysis was performed by dividing the cohort into 2 groups based on BMI: those patients with BMI $<30 \mathrm{~kg} / \mathrm{m}^{2}$ and those with $\mathrm{BMI}>30 \mathrm{~kg} / \mathrm{m}^{2}$. For the analysis of the entire cohort, patients were classified into 3 groups based on BMI (normal, overweight and obese, as defined above).

Initial preoperative data collected included age, serum prostate-specific antigen (PSA) levels, clinical stage, biopsy Gleason score, BMI, prostate gland volume and international index erectile function score. The following outcomes were evaluated: overall duration of surgery, length of individual steps during the procedure, estimated blood loss, length of stay, postoperative complications (leaks and incisional hernia) and pathological outcomes. Length of stay was defined as the time from entry to the hospital to the time of discharge.

The surgical technique was an intraperitoneal antegrade approach with early division of the bladder neck, using the original DaVinci robotic system, as previously described. ${ }^{12}$ Until case number 72, the 3-arm DaVinci system was used; subsequent to that, the 4-arm DaVinci system was used. A standard pelvic lymph node dissection (as described in
Cancer Care Ontario guidelines ${ }^{13}$ ) was performed for intermediate-risk patients or for low-risk patients with lymphadenopathy identified at the time of surgery. Neurovascular bundle preservation, when performed, was recorded as either unilateral or bilateral. Intraoperatively, a non-operating member of the surgical team recorded the time taken for individual steps onto the patient case report form. The dorsal vein complex was ligated using a vicryl suture. The prostatic vascular pedicles were ligated using either clips or the harmonic scalpel (until case 30 ). ${ }^{12}$ A running anastomosis was performed, and a drain was left in situ in all cases. Postoperatively, patients were discharged with their Foley catheter. Cystograms were only performed if there was increased drain output and drain fluid demonstrated elevated creatinine suggestive of a urinary leak.

For statistical analysis, the Kruskal-Wallis equality-of-populations rank test or Wilcoxon two-sample test were used for continuous variables. A chi-square or Fisher's exact test were used for statistical analysis of categorical variables. The impact of BMI on operative time, estimated blood loss and length of stay was modeled using linear regression analysis, whereas the impact of BMI on surgical margin status, pathological upgrading and pathological upstaging was assessed using logistic regression analysis.

\section{Results}

\section{Learning curve: initial 50 Cases}

The initial 50 cases were divided into 2 groups (BMI $<30 \mathrm{~kg} /$ $\mathrm{m}^{2}$ and $\left.\mathrm{BMI}>30 \mathrm{~kg} / \mathrm{m}^{2}\right)$ for statistical analysis. There were 14 obese patients (28\%) with a mean BMl of $33 \mathrm{~kg} / \mathrm{m}^{2}$. These 2 groups were statistically similar with regards to preoperative serum PSA, clinical stage and biopsy Gleason score (Table 1).

\begin{tabular}{lccc}
\hline \multicolumn{4}{c}{ Table 1. Patient characteristics for initial 50 cases } \\
\hline & BMI $<30$ & BMI $>\mathbf{3 0}$ & $\boldsymbol{p}$ value \\
\hline Patients, $\mathrm{n}$ & 36 & 14 & \\
\hline Mean age & 62.3 & 58.2 & 0.03 \\
\hline Mean PSA (ng/mL) & 6.9 & 6.8 & 0.89 \\
\hline BMI (mean) & 26.8 & 33.2 & $<0.01$ \\
\hline Baseline IIEF (mean) & 15.9 & 16.4 & 0.98 \\
\hline Preoperative & & & 0.89 \\
Gleason sum, $\mathrm{n}$ & & 0 & \\
5 & $2(5.6 \%)$ & $11(78.6 \%)$ & \\
6 & $24(66.6 \%)$ & $3(21.4 \%)$ & \\
7 & $10(27.8 \%)$ & & 1.00 \\
\hline Clinical stage, $\mathrm{n}$ & & $11(78.6 \%)$ & \\
T1 & $27(75 \%)$ & $3(21.4 \%)$ & \\
T2 & $9(25 \%)$ & \\
\hline
\end{tabular}

$\mathrm{BMI}=$ body mass index; $\mathrm{PSA}=$ prostate-specific antigen; IIEF = international index of erectile dysfunction. 


\begin{tabular}{|c|c|c|c|}
\hline & $\mathrm{BMI}<30$ & $\mathrm{BMI}>\mathbf{3 0}$ & $p$ value \\
\hline Operative time, $\min$ & 243 & 253 & 0.39 \\
\hline Insertion of ports, min & 25.7 & 22.7 & 0.49 \\
\hline Robot docking, min & 6.7 & 6.9 & 0.87 \\
\hline Bladder mobilization & 23.1 & 27.6 & 0.42 \\
\hline Apex & 24.2 & 22.9 & 0.25 \\
\hline Anastomosis & 49.2 & 48.8 & 0.90 \\
\hline Estimated blood loss, mL & 451 & 457 & 0.78 \\
\hline Hospital stay, days & 2.9 & 4.3 & 0.04 \\
\hline Postoperative urinary leak, $n$ & 2 & 1 & 1.00 \\
\hline Incisional hernia, n & 2 & 1 & 1.00 \\
\hline Pathological stage, $n$ & & & 0.15 \\
\hline pT2 & 26 & 13 & \\
\hline pT3 & 10 & 1 & \\
\hline Positive margins, n (\%) & $14(38.9 \%)$ & $3(21.4 \%)$ & 0.33 \\
\hline
\end{tabular}

Two patients (a patient with a $\mathrm{BMI}>30 \mathrm{~kg} / \mathrm{m}^{2}$ and the other patient with a $\mathrm{BMI}<30 \mathrm{~kg} / \mathrm{m}^{2}$ ) required conversion to open surgery for failure to progress. There was no statistically significant difference in overall operative times and no difference in the individual operative steps (Table 2). No differences were noted with regards to estimated blood loss, or the postoperative complications of urinary leak (Clavien grade I complication) or incisional hernia (Clavien grade IIIb complication). Only 1 patient in this cohort required a blood transfusion (Clavien grade II complication). Obese patients had a longer length of hospital stay (4.3 days vs. 2.9 days; $p=0.04$ ) compared with non-obese patients. There were no differences in margin status or pathological stage.

On multiple linear regression analysis, after controlling for variables which may have influenced length of hospital stay (age, operative time and presence of a urinary leak), BMI remained a significant predictor of increased length of stay $(p=0.002)$.

\section{Entire cohort}

This cohort of 153 patients was divided into 3 groups based on BMI, with 28 patients (18.3\%) classified as normal (BMI $\left.<25 \mathrm{~kg} / \mathrm{m}^{2}\right), 85$ patients $(55.6 \%$ ) classified as overweight (BMI $\left.25-30 \mathrm{~kg} / \mathrm{m}^{2}\right)$, and 40 patients $(26.1 \%)$ classified as obese $\left(\mathrm{BMI}>30 \mathrm{~kg} / \mathrm{m}^{2}\right)$. These 3 groups were statistically similar with regards to preoperative serum PSA, clinical stage and biopsy Gleason score (Table 3). Lymph node dissection was performed in 40 patients (26\%) with intermediate-risk disease; there was no statistically significant difference in the proportions of normal, overweight and obese patients undergoing lymph node dissection. Unilateral neurovascular bundle preservation was performed in 41 patients (27.2\%); bilateral

\begin{tabular}{|c|c|c|c|c|}
\hline & $\mathrm{BMI}<30$ & BMI 25-30 & $\mathrm{BMI}>\mathbf{3 0}$ & $p$ value \\
\hline Patients, $\mathrm{n}$ & 28 & 85 & 40 & \\
\hline Mean age & 63.5 & 59.9 & 57.9 & $<0.01$ \\
\hline $\begin{array}{l}\text { Mean PSA } \\
\text { (ng/mL) }\end{array}$ & 7.3 & 6.7 & 6.6 & 0.55 \\
\hline BMI (mean) & 22.8 & 27.2 & 32.4 & $<0.01$ \\
\hline $\begin{array}{l}\text { Baseline IIEF } \\
\text { (mean) }\end{array}$ & 17.3 & 17.4 & 17.9 & 0.95 \\
\hline $\begin{array}{l}\text { Preoperative } \\
\text { Gleason sum, n }\end{array}$ & & & & 0.45 \\
\hline 5 & $1(3.6 \%)$ & $1(1.2 \%)$ & 0 & \\
\hline 6 & $15(53.6 \%)$ & $60(70.6 \%)$ & $29(72.5 \%)$ & \\
\hline 7 & $12(42.9 \%)$ & $24(28.2 \%)$ & $11(27.5 \%)$ & \\
\hline Clinical stage, $\mathrm{n}$ & & & & 0.52 \\
\hline $\mathrm{T} 1$ & $18(64.3 \%)$ & $62(72.9 \%)$ & $30(76.8 \%)$ & \\
\hline $\mathrm{T} 2$ & $10(35.7 \%)$ & $23(27.1 \%)$ & $9(23.1 \%)$ & \\
\hline
\end{tabular}

$\mathrm{BMI}=$ body mass index; $\mathrm{PSA}=$ prostate-specific antigen; IIEF = International Index of Erectile Dysfunction.

neurovascular bundle preservation in 73 patients $(48.3 \%)$; and neurovascular bundle resection in 37 patients (24.5\%). There was no statistically significant difference in neurovascular bundle preservation proportions between groups.

There were no statistically significant differences between the 3 groups with regards to overall operative time. Analyzing individual steps of the procedure showed that there was a statistically significant difference in bladder mobilization time, however this difference is not clinically significant (18 minutes in the normal group vs. 21 minutes in the overweight group vs. 20 minutes in the obese group). There was no statistically significant difference in estimated blood loss (although a trend was apparent for increasing blood loss with increasing BMI), or the occurrence of the postoperative complications of urinary leak (Clavien grade I complication) and incisional hernia (Clavien grade IIIb complication). One patient (normal BMI) suffered a myocardial infarction postoperatively (Clavien grade IVd complication), and another patient (obese) developed a deep venous thrombosis (Clavien grade Ild complication). There were no statistically significant differences in the length of stay, pathological stages or margin status (Table 4).

As there is some loss of information when using a continuous variable, such as BMI as a categorical variable, linear regression models were used to assess whether BMI predicted for increased operative time, blood loss or length of stay. After adjusting for age and prostate volume, using a linear regression model, BMI was a significant predictor of increased operative time ( $p=0.007)$, but not blood loss or length of stay. On logistic regression modelling, BMI was not a significant independent predictor of pathological stage, pathological upgrading, pathological upstaging or margin status. 


\begin{tabular}{|c|c|c|c|c|}
\hline & $\mathrm{BMI}<30$ & BMI 25-30 & BMI > 30 & $p$ value \\
\hline $\begin{array}{l}\text { Operative time, } \\
\text { min }\end{array}$ & 198 & 210 & 215 & 0.25 \\
\hline $\begin{array}{l}\text { Insertion of ports, } \\
\text { min }\end{array}$ & 22.4 & 24.0 & 23.2 & 0.87 \\
\hline $\begin{array}{l}\text { Robot docking, } \\
\text { min }\end{array}$ & 5.3 & 5.4 & 5.8 & 0.57 \\
\hline $\begin{array}{l}\text { Bladder } \\
\text { mobilization }\end{array}$ & 18 & 21.5 & 20.1 & 0.05 \\
\hline Apex & 17 & 15.9 & 17.6 & 0.34 \\
\hline Anastomosis & 46.1 & 46 & 45.4 & 0.98 \\
\hline $\begin{array}{l}\text { Estimated blood } \\
\text { loss, } \mathrm{mL}\end{array}$ & 193 & 298 & 350 & 0.06 \\
\hline $\begin{array}{l}\text { Hospital stay, } \\
\text { days }\end{array}$ & 3.2 & 2.9 & 3.8 & 0.14 \\
\hline $\begin{array}{l}\text { Postoperative } \\
\text { urinary leak, n }\end{array}$ & 1 & 7 & 3 & 0.83 \\
\hline $\begin{array}{l}\text { Incisional hernia, } \\
\mathrm{n}\end{array}$ & 1 & 2 & 2 & 0.71 \\
\hline $\begin{array}{l}\text { Pathological } \\
\text { stage, } n\end{array}$ & & & & 0.29 \\
\hline pT2 & 21 & 59 & 33 & \\
\hline pT3 & 5 & 25 & 7 & \\
\hline $\begin{array}{l}\text { Positive margins, } \\
\mathrm{n}(\%)\end{array}$ & $\begin{array}{c}6 \\
(21.4 \%) \\
\end{array}$ & $\begin{array}{c}21 \\
(24.7 \%) \\
\end{array}$ & $\begin{array}{c}9 \\
(22.5 \%) \\
\end{array}$ & 0.95 \\
\hline
\end{tabular}

\section{Discussion}

There is no clear definition for how many cases constitutes the learning curve for RARP; some estimates range from 12 to 20 cases. ${ }^{14-16}$ However, anecdotally, as the technique has continued to evolve, high-volume robotic surgeons have noted that their results continue to improve even after several hundred cases. In open radical prostatectomy, the learning curve has been postulated to be around 250 cases. $^{17}$ We have attempted to define the impact of obesity on the learning curve, and have done our analysis on the initial 50 cases, as well as the initial 153 cases. This has been done due to the varying definitions of the learning curve noted in the literature.

Obesity, defined as a BMI $>30 \mathrm{~kg} / \mathrm{m}^{2}$, had a prevalence overall of $26.1 \%$ in our cohort, which is similar to the population prevalence as estimated by the CDC. We found, on linear regression analysis, that BMI was an independent predictor of increased length of stay in our initial 50 cases, but not in the entire cohort. Although our study was not designed specifically to address the reason for this, possible explanations include increased ileus in obese patients, longer times to mobilize, or the data being skewed by the small absolute numbers of obese patients in the initial 50 cases (14 patients were obese). Interestingly, this trend of prolonged hospitalization in obese patients did not continue throughout the entire cohort. Body mass index was also an independent predictor of increased operative time in the entire cohort, after controlling for age and prostate volume, but not in the initial 50 cases. Similar findings, with regards to increased operative times for RARP in obese patients, have been found in other studies, $7,10,11,18,19$ but conflicting findings have also been reported. ${ }^{9,20}$ One possible reason for this is that most studies did not do a linear regression and control for patient age and prostate volume, both of which may affect operative times. Importantly, however, the differences in operative times in our cohort are unlikely to be of clinical significance (normal BMI 198 minutes vs. overweight 210 minutes vs. obese 215 minutes).

The remainder of our findings is somewhat at odds with what has been previously published in this area. We found no statistically significant difference in estimated blood loss, in our initial 50 cases and in the entire cohort; BMI was not an independent predictor of increased blood loss on linear regression modelling. These results contrast with previously published reports, which have noted differences in estimated blood loss, but not in transfusion rates. ${ }^{7,11,18,19}$ Differences in estimated blood loss, however, in the absence of transfusion, are unlikely to be of clinical significance. Furthermore, after controlling for age and prostate volume, it is possible that $\mathrm{BMI}$ may no longer be an independent predictor for increased blood loss in RARP.

Higher rates of positive surgical margins in obese patients after RARP have been reported. ${ }^{11}$ We found no such difference in our learning curve nor in the entire cohort; on logistic regression analysis, BMI was not an independent predictor of positive surgical margins. We found no difference in pathological stages.

Comparisons between studies in this area are somewhat difficult, as BMI has been used by some groups as a categorical variable, while others have used it as a continuous variable in their analysis. Also, when making comparisons, some authors have created 2 groups (e.g., BMl $<30 \mathrm{~kg} / \mathrm{m}^{2} \mathrm{vs}$. $\mathrm{BMI}>30 \mathrm{~kg} / \mathrm{m}^{2}$ ), while others have created 3 groups (normal vs. overweight vs. obese). With larger series, it may also be possible to include a fourth group, the morbidly obese patient (i.e., BMI $>35 \mathrm{~kg} / \mathrm{m}^{2}$ ). Furthermore, the technique may also vary, with some surgeons using an intraperitoneal approach and others using an extraperitoneal approach.

The limitations of our work include the small sample size, and the fact that only $26 \%$ of patients within the cohort were obese. Ideally, to obtain a large enough sample size of the learning phase of RARP, multiple cohorts from several institutions should be pooled to obtain a large sample, which only includes patients within the learning curve. However, it will nevertheless be difficult to obtain a consensus on when the learning curve ends. 


\section{Conclusion}

Obese patients have an increased risk of longer length of hospital stay, but not of prolonged operative time, increased blood loss, positive surgical margins or the postoperative complications of incisional hernia and leak during the initial part of the learning curve (defined as the initial 50 cases). In the entire cohort, BMI was noted to predict a minor increase in operative time only, with all other perioperative outcomes being similar to the non-obese patient.

In conclusion, BMI does not seem to have a significant impact on perioperative outcomes after RARP. Further multiinstitutional studies, which pool multiple cohorts of the initial 50 cases together, are needed to confirm our findings.

Divisions of Urology and Surgical Oncology, Departments of Surgery and Oncology, University of Western Ontario, London, ON

Competing interests: None declared.

This paper has been peer-reviewed.

\section{References}

1. Centers for Disease Control and Prevention (CDC). State-specific prevalence of obesity among adults-United States, 2007. MMWR Morb Mortal Wkly Rep 2008;57:765-8.

2. Berghofer A, Pischon T, Reinhold T, et al. Obesity prevalence from a European perspective: a systematic review. BMC Public Health 2008;8:200.

3. Zhang YX, Wang SR. Distribution of body mass index and the prevalence changes of overweight and obesity among adolescents in Shandong, China from 1985 to 2005. Ann Hum Biol 2008;35:547-55.

4. Chow CK, Naidu S, Raju K, et al. Significant lipid, adiposity and metabolic abnormalities amongst 4535 Indians from a developing region of rural Andhra Pradesh. Atherosclerosis 2008;196:943-52.
5. Zaninotto P, Head J, Stamatakis E, et al. Trends in obesity among adults in England from 1993 to 2004 by age and social class and projections of prevalence to 2012. J Epidemiol Community Health 2009;63:140-6. Epub 2008 Dec 11.

6. Adams KF, Schatzkin A, Harris TB, et al. Overweight, obesity, and mortality in a large prospective cohort of persons 50 to 71 years old. N Engl J Med 2006;355:763-78.

7. Ahlering TE, Eichel L, Edwards R, et al. Impact of obesity on clinical outcomes in robotic prostatectomy. Urology 2005;65:740-4.

8. Wiltz AL, Shikanov S, Eggener SE, et al. Robotic radical prostatectomy in overweight and obese patients: oncological and validated-functional outcomes. Urology 2009; 73:316-22.

9. Khaira HS, Bruyere F, O'Malley PJ, et al. Does obesity influence the operative course or complications of robot-assisted laparoscopic prostatectomy. BJU Int 2006;98:1275-8.

10. Mikhail AA, Stockton BR, Orvieto MA, et al. Robotic-assisted laparoscopic prostatectomy in overweight and obese patients. Urology 2006;67:774-9.

11. Castle EP, Atug F, Woods $M$, et al. Impact of body mass index on outcomes after robot assisted radical prostatectomy. World J Urol 2008;26:91-5.

12. Chin JL, Luke PP, Pautler SE. Initial experience with robotic-assisted laparoscopic radical prostatectomy in the Canadian health care system. Can Urol Assoc J 2007:1:97-101.

13. Chin J, Srigley J, Mayhew LA, et al. Guideline for Optimization of Surgical and Pathological Quality Performance for Radical Prostatectomy in Prostate Cancer Management: Surgical and Pathological Guidelines. Cancer Care Ontario: Program in Evidence-Based Care 2008. http://www.cancercare.on.ca/ toolbox/qualityguidelines/clin-program/surgery-ebs/Accessed July 11, 2010.

14. Wu ST, Tsui KH, Tang SH, et al. Laparoscopic radical prostatectomy: initial experience of robotic surgery in Taiwan. Anticancer Res 2008;28:1989-92

15. Ahlering TE, Skarecky D, Lee D, et al. Successful transfer of open surgical skills to a laparoscopic environment using a robotic interface: initial experience with laparoscopic radical prostatectomy. J Urol 2003;170:1738-41.

16. Patel VR, Tully AS, Holmes R, et al. Robotic radical prostatectomy in the community setting-the learning curve and beyond: initial 200 cases. J Urol 2005;174:269-72.

17. Klein EA, Bianco FJ, Serio AM, et al. Surgeon experience is strongly associated with biochemical recurrence after radical prostatectomy for all preoperative risk categories. J Urol 2008;179:2212-6.

18. Boorijan SA, Crispen PL, Carlson RE, et al. Impact of obesity on clinicopathologic outcomes after robotassisted laparoscopic prostatectomy. J Endourol 2008;22:1471-6.

19. Herman MP, Raman JD, Dong $S$, et al. Increasing body mass index negatively impacts outcomes following robotic radical prostatectomy. J Soc Laparoendosc Surg 2007;11:438-42.

20. Boczko J, Madeb R, Golijanin D, et al. Robot-assisted radical prostatectomy in obese patients. Can J Urol 2006;13:3169-73

Correspondence: Dr. S.E. Pautler, Assistant Professor, Divisions of Urology and Surgical Oncology, Departments of Surgery and Oncology, University of Western Ontario St. Joseph Health Care, 268 Grosvenor St., London, 0N N6A 4V2; fax 519-646-6037; Stephen.Pautler@sihc.london.on.ca 